\title{
Utility-Taguchi based hybrid optimization approach in machining of graphite composites
}

\author{
Jogendra Kumar ${ }^{1}$, Prakhar Kumar Kharwar ${ }^{1}$, Rajesh Kumar Verma ${ }^{1 *}$ \\ $I^{I^{*}}$ Department of Mechanical Engineering, Madan Mohan Malaviya University of Technology, Gorakhpur, INDIA \\ "Corresponding Author: e-mail: rkvme@mmmut.ac.in, Tel +91-8400444068
}

\begin{abstract}
In the present scenario, composites material is widely used in various engineering areas like satellite components, aircraft parts, chemical and sports industries. Graphite is an allotrope of carbon that possesses various electrical and mechanical properties. In this paper, graphite is taken as reinforcement into the epoxy matrix. In this study, the hybrid optimization module is developed to tackle multi-objective machining performance optimization issues. Utility concept coupled Taguchi approach is used to find out optimum values of responses in three input factors i.e., drill speed, feed rate and fiber volume percentage varied at four discrete levels and surface roughness (Ra) and material removal rate (MRR) are taken as process response. Taguchi $\mathrm{L}_{16}$ OA has been used to perform the machining operation. Multiple responses aggregated into a single function i.e., overall utility (U) and finally optimized by the Taguchi concept. Utility embedded Taguchi approach determined the favorable machining setting which the confirmatory test has verified shows satisfactory results. ANOVA outcomes reveal that feed rate $(73.37 \%)$ is the most important factor trailed by drill speed $(3.44 \%)$ and fiber volume percentage.
\end{abstract}

Keywords: CNC, Graphite Reinforced Polymer Composite, Surface roughness, ANOVA.

Cite this article as:

Kumar J., Kharwar P.K., Verma R.K. 2021. Utility-Taguchi based hybrid optimization approach in machining of graphite composites, International Journal of Engineering, Science and Technology, Vol. 13, No. 1, pp. 10-16. doi: 10.4314/ijest.v13i1.2S

Received: December 1, 2019; Accepted: February 5, 2021; Final acceptance in revised form: March 31, 2021

This paper was earlier presented at the International Conference on Energy, Environment \& Material Sciences (ICE2M), 1-3 December 2019 and substantially improved for this Special Issue. Guest Editor: Dr. Sri Niwas Singh, Professor (HAG), Department of Electrical Engineering, Indian Institute of Technology Kanpur, 208016 (U.P.) India, former Vice-Chancellor, Madan Mohan Malviya University of Technology Gorakhpur (April 2017 to July 2020).

\section{Introduction}

Composite is the combination of two or more constituents that outcome best properties and high performance parametric than the individual materials. Basically, the constituents divided into two terms, reinforcements and matrix. The reinforcement phase provides the base for composite materials, so it very harder than the matrix phase. Polymer-based composite materials have less capability to sustain heat and are unable to plain thermal application. The various researchers have been distracted from improving the polymer composite's thermal properties. So, there have various filler materials used to increase the thermal as well as mechanical properties. Due to its superior properties like high strength, stiffness reduced weight composite materials are used in various fields such as aircraft, automotive and several other industries. Thus, it is necessary to machine the material at various stages. The graphite-polymer composite's basic characteristics have a 10 times higher rigidity than the glass fiber and density (1.8$2 \mathrm{~g} \mathrm{~cm}^{-3}$ ) half of Gfs. It has excellent thermal and electrical properties and less in rupture compared to Gfs and aramids material. 
(Bhatnagar et al., 2004) studied critical issues related to the machining of graphite-reinforced polymer composites and investigated the relationship among the point geometry, cutting speed, hole diameter, feed, point geometry, thrust force \& material width during the drilling process. Finally, established a mathematical model to assess the damage due to cutting speed and feed. (Krishnaraj et al., 2012) concluded experimentally optimal cutting situations at speed and feed for CFRP drilling and illustrated the "peel up - push out" concept in the epoxy matrix. Finally, carried out the variance contribution rate using the ANOVA. Yu et al reported a procedure to convert natural graphite into graphite Nano polymer composite to enhance the thermal conductivity using acid intercalation. (Ganguli et al., 2008) prepared a graphite-epoxy composite with a different weight of percentage of graphite filled epoxy and enhanced the thermal, electrical properties over the pure epoxy. (Choi and Chang, 1992) Chang carried out a robust model to predicted damage stress analysis of graphite-epoxy composite and finally verified the tested data. (Tserpes et al., 2002) applied a FEM solution to predict the failure analysis under a bolted joint's strength in graphite-epoxy composites material. They were concluded that the failure of the joint affected by the failure degradation law and result was well agreed within $7 \%$ to the experimental.

(Kumar and Singh, 2019) conducted an experimental procedure to study a mechanism of cutting force and tool geometry of graphite-epoxy composites. (Verma et al., 2017) reported the optimized machining parameter to improve the productivity and the quality using the utility concept-based Taguchi approach. Taguchi L16 orthogonal array used for the design of the experiment at different levels of process parameters. (Hansda and Banerjee, 2014) reduced the delamination factor by the selection of optimized process parameters with the help of the utility-based Taguchi approach. (Vasudevan et al., 2014) applied a hybrid optimization technique to optimize the machining process parameter to improve productivity and quality of the product. (Krishnamoorthy et al., 2012) optimized the graphite-reinforced polymer composite drilling performances using a fuzzy concept. The combined approach of the Fuzzy and Taguchi process was used for machining characteristics optimization. (Kim, 2016) employed High-Speed Steel \& carbide drills during drilling of GrlBi (graphite fiber bisimide) complex and titanium alloy (TiAlloy) stacks. Carbides consuming greater hot toughness were found to accomplish better than consistent High-Speed Steel drills.

\section{Methodology}

\subsection{Taguchi Approach}

Taguchi based design of experiments (DOE) array was used to execute the machining operation. Taguchi concept is used to examine the machining parameter's influence over the lowest number of experimentations(Biswas et al., 2012; Rahul et al., 2018). The Taguchi method is used for the single response's statistical scale and used for computing the signal to noise ratio ( $\mathrm{S} / \mathrm{N}$ ratio)(Goswami and Kumar, 2014). Finally, the S/N ratio gives the optimal setting from the graph. In this study, the MRR of the process used as maximizing factor and surface roughness is considered lower than the better (LB) type.

Higher the Better (HB):

$$
(\mathrm{S} / \mathrm{N})_{\mathrm{ij}}=-10 \log \left(\frac{1}{n} \sum_{j=1}^{n} 1 / X_{i j}^{2}\right)
$$

Lower the Better (LB):

$$
\mathrm{N}_{\mathrm{ij}}=-10 \log \left(\frac{1}{n} \sum_{j=1}^{n} X_{i j}^{2}\right)
$$

Where $(\mathrm{S} / \mathrm{N})_{\mathrm{ij}}$ is $\mathrm{S} / \mathrm{N}$ ratio, $X_{i j}^{2}$ is measured significance data of the $\mathrm{i}_{\mathrm{th}}$ experimentation at the $\mathrm{j}_{\mathrm{th}}$ assessment.

A cause-effect diagram Fig 1, recognizes direct and indirect probable factors that affect the machining process. From the above literature survey on drilling, a total of three numbers machine parameters were selected at four discrete levels.

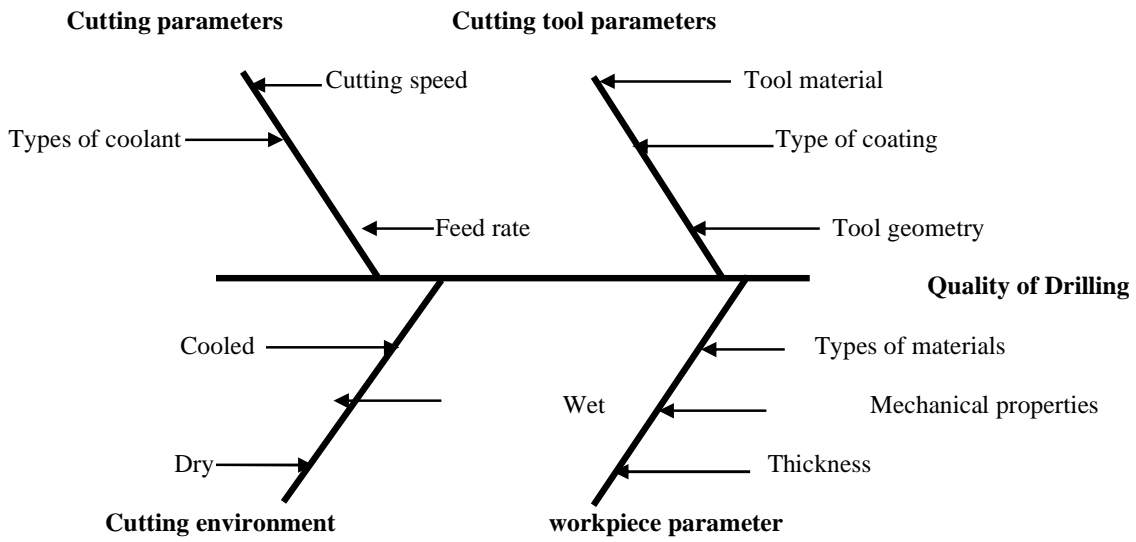

Fig. 1. Causes and effect diagram of the drilling process 


\subsection{Utility Concepts}

The Utility concept is defined as a selection of performance numbers based on a logarithmic scale. This scale is falling under the specific range and converts the individual response into degrees performance utilities. Thus, it is useful to optimization the multiobjective response parameter. The concept of utility theory consists of the following steps:

1) Suppose $K_{i}$ describes the preference number from given a choice and applying utility concept, then expression becomes as

Where $\mathrm{U}_{1}\left(\mathrm{~K}_{1}\right)=$ utility $\mathrm{i}^{\text {th }}$ function of choices.

$$
\mathrm{U}\left(\mathrm{K}_{1}, \mathrm{~K}_{2}, \mathrm{~K}_{3} \ldots \ldots \ldots \ldots \ldots \mathrm{Kn}\right)=f\left\{\mathrm{U}_{1}\left(\mathrm{~K}_{1}\right), \mathrm{U}_{2}\left(\mathrm{~K}_{2}\right)\right\}
$$

2) find out the overall utility of specific utility expression as given

$$
\mathrm{U}\left(\mathrm{K}_{1}, \mathrm{~K}_{2}, \ldots \ldots \ldots \ldots \mathrm{Kn}\right)=\sum_{i=1}^{n} U_{i}\left(K_{i}\right)
$$

3) The stipulated weight on to emphasis, after deciding the weight and overall utilities expressed as

$$
\mathrm{U}\left(\mathrm{K}_{1}, \mathrm{~K}_{2}, \ldots \ldots \ldots \ldots . . . \mathrm{K}_{\mathrm{n}}\right)=\sum_{i=1}^{n} W_{i} U_{i}\left(K_{i}\right)
$$

Here, let summation of weight is 1 choice scale denote between two numbers 0 to 9 for accepted quality.

4) Calculated preferential number $\mathrm{Pi}$

$$
\mathrm{P}_{\mathrm{i}}=\mathrm{C} \times \log \left(\frac{K_{i}}{K_{i}^{*}}\right)
$$

Therefore $\mathrm{C}=\frac{9}{\log \frac{K^{*}}{K_{i}}}$

Where, $\mathrm{A}=$ constant and $\mathrm{K}^{*}=$ Best values

5) Finally, find out the overall utility expressed by the equation

\section{Experimental Details}

$$
\mathrm{U}=\sum_{i=1}^{n} W_{i} P_{i}
$$

\subsection{Work and Tool Materials}

The drilling was performed on CNC setup and the rate of material removal (MRR) and roughness of surface were considered as machining performances. The machine parameters namely, feed rate, spindle speed, and the fiber volume percentage are used in current work. The experiment has been conducted on a vertical CNC machine, using the HSS drill bit ( $\phi 10 \mathrm{~mm})$. It has maximum spindle speed $2500 \mathrm{rpm}$ with a $4.5 \mathrm{KW}$ motor as shown in Fig 2. Surface roughness measured by Taylor Hobson Surtronic S128 roughness tester and MRR measured by general mathematical formulae. The graphite-reinforced polymer composite was made of $70 \mathrm{gm}$ epoxy resin using graphite content (by weight varying as 10\%, $20 \%, 30 \%, 40$ ). The specimen is manufactured by heating and pouring of materials into the mold. The prepared sample as shown in Fig 3. This method is known as a casting method that can be made a variety of shapes or thicknesses with varying graphite weight percentages. Graphite (Mesh size 200) was supplied by Aakar carbon Pvt Ltd Jharkhand, India. Sample $(7.8 \times 8 \times 1 \mathrm{~cm})$ was prepared by combining LAPOX epoxy, hardener K-6, and graphite varying weight percentages (Fig 4).

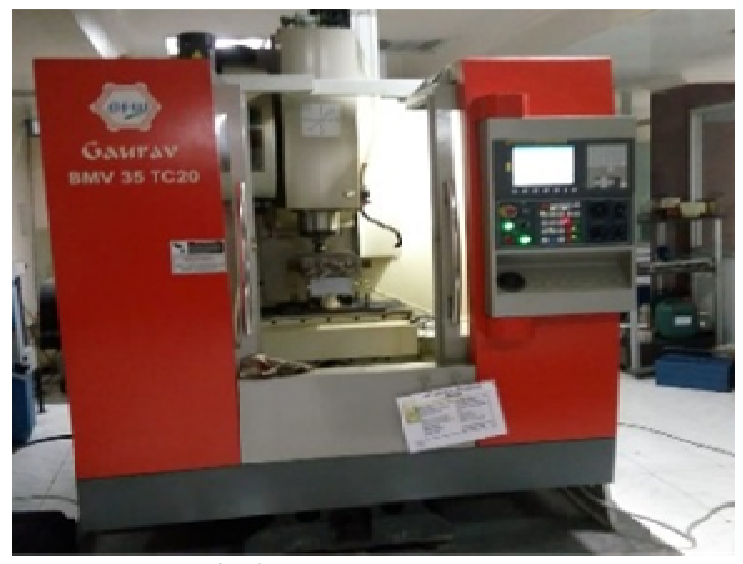

Fig. 2. CNC vertical drilling machine 


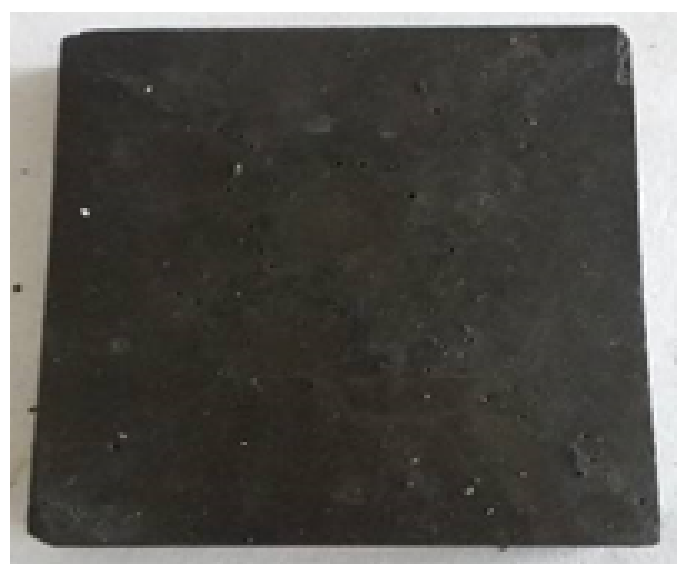

Fig. 3. Graphite reinforced a composite specimen

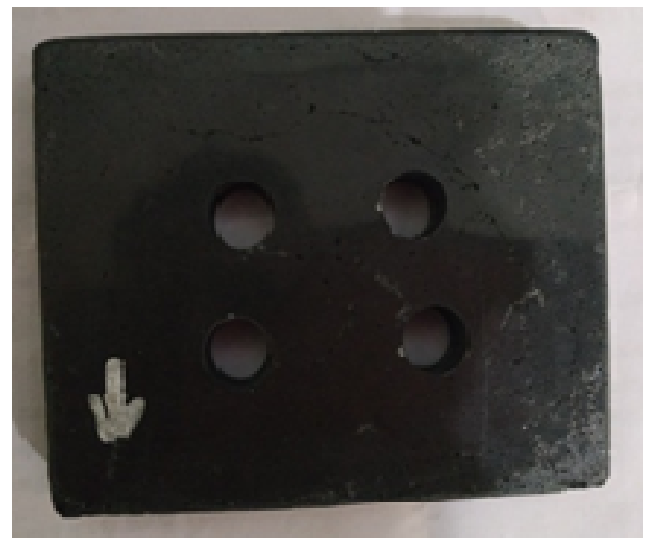

Fig. 4. Composite sample after machining

\subsection{Design of experiments}

In order to recognize the process parameter that affects the drilling parts to influences the quality of the drill part. There are three input parameters viz; drill speed, feed rate and fiber volume percentage with four different levels as depicted in Table 1. The experimental input parameter was listed in Table 2. In the present work, Taguchi-based $\mathrm{L}_{16}$ orthogonal array (Mini tab18) has considered for the experiment as depicted in Table 2 and the overall utility Table 3, respectively.

Table 1: Process parameters for different level

\begin{tabular}{|c|c|c|c|c|c|}
\hline \multirow{2}{*}{ Factor } & \multirow{2}{*}{ Units } & \multicolumn{4}{|c|}{ Significance of Level } \\
\cline { 3 - 6 } & & Level 1 & Level 2 & Level 3 & Level 4 \\
\hline Drill speed & Rpm & 1000 & 1500 & 2000 & 2500 \\
\hline Feed rate & mmlrev & 150 & 200 & 250 & 300 \\
\hline FVP & $\%$ & 10 & 20 & 30 & 40 \\
\hline
\end{tabular}

Table 2: Taguchi $\mathrm{L}_{16}$ orthogonal array

\begin{tabular}{|c|c|c|c|c|c|}
\hline Exp. No. & Drill rotational speed $(\mathbf{r p m})$ & Feed rate $(\mathbf{m m} / \mathbf{r e v})$ & $\mathbf{F V P}(\boldsymbol{\%})$ & $\mathbf{M R R}\left(\mathbf{m m}^{\mathbf{3}} \mathbf{/ s e c}\right)$ & $\mathbf{R a}(\mathbf{a v g})(\boldsymbol{\mu m})$ \\
\hline 1 & 1000 & 150 & 10 & 10.98 & 1.8 \\
\hline 2 & 1000 & 200 & 20 & 12.27 & 1.3 \\
\hline 3 & 1000 & 250 & 30 & 16.36 & 0.6 \\
\hline 4 & 1000 & 300 & 40 & 19.21 & 1.3 \\
\hline 5 & 1500 & 150 & 20 & 7.587 & 1.1 \\
\hline 6 & 1500 & 200 & 10 & 12.35 & 1.5 \\
\hline 7 & 1500 & 250 & 40 & 16.42 & 1.8 \\
\hline 8 & 1500 & 300 & 30 & 19.90 & 1.3 \\
\hline 9 & 2000 & 150 & 30 & 8.01 & 0.9 \\
\hline 10 & 2000 & 200 & 40 & 12.06 & 1.7 \\
\hline 11 & 2000 & 250 & 10 & 16.47 & 1.9 \\
\hline 12 & 2000 & 300 & 20 & 20.63 & 2.9 \\
\hline 13 & 2500 & 150 & 40 & 8.29 & 1.0 \\
\hline 14 & 2500 & 200 & 30 & 12.30 & 1.0 \\
\hline 15 & 2500 & 250 & 20 & 18.16 & \\
\hline 16 & 2500 & 300 & 10 & 19.61 & \\
\hline
\end{tabular}

Table 3: Overall utility with $\mathrm{S} / \mathrm{N}$ ratio

\begin{tabular}{|c|c|c|c|c|c|}
\hline Exp. No. & Pi MRR & Pi Ra & U overall & S/N RA & P S/N RA \\
\hline 1 & 3.325721409 & 2.0716857 & 2.698704 & 8.6231 & 18.2781 \\
\hline 2 & 4.32514792 & 4.1239372 & 4.224543 & 12.5156 & \\
\hline 3 & 6.913484004 & 9.0000000 & 7.956742 & 18.0147 & \\
\hline 4 & 8.358360801 & 4.1239372 & 6.241149 & 15.9053 & \\
\hline 5 & 0.000000000 & 5.177451 & 2.588725 & 8.2617 & \\
\hline
\end{tabular}


Table 3 (cont'd): Overall utility with S/N ratio

\begin{tabular}{|c|c|c|c|c|c|}
\hline Exp. No. & Pi MRR & Pi Ra & U overall & S/N RA & P S/N RA \\
\hline 6 & 4.383619029 & 3.2214827 & 3.802551 & 11.6015 & \\
\hline 7 & 6.946420747 & 2.0716857 & 4.509053 & 13.0817 & \\
\hline 8 & 8.675861148 & 5.7785173 & 7.227189 & 17.1794 & \\
\hline 9 & 0.488139185 & 4.1239372 & 2.306038 & 7.2573 & \\
\hline 10 & 4.169828473 & 6.4429653 & 5.306397 & 14.4960 & \\
\hline 11 & 6.973776227 & 2.4321509 & 4.702964 & 13.4474 & \\
\hline 12 & 9.000000000 & 1.7307149 & 5.365357 & 14.5920 & \\
\hline 13 & 0.797276203 & 1.7307149 & 1.263996 & 2.0349 & \\
\hline 14 & 4.34711914 & 0.0000000 & 2.17356 & 6.7434 & \\
\hline 15 & 7.85263118 & 5.7785173 & 6.815574 & 16.6700 & \\
\hline 16 & 8.543781278 & 5.7785173 & 7.161149 & 17.0997 & \\
\hline
\end{tabular}

The Taguchi approach transforms the machining characteristic values into the $\mathrm{S} / \mathrm{N}$ ratio using the desired criteria of the responses i.e., higher the better or lower is better. From Fig. 5 the optimum parameter setting is found as A1B4C1. The predicted S/N ratio of overall utility are observed as 18.2781 which the highest among all the sixteen performed experiments. This higher value of the $\mathrm{S} / \mathrm{N}$ ratio is highly desired for an efficient machining environment for drilling of graphite-epoxy composites. Also, the outcomes of the confirmatory test satisfactory agreement with the actual ones.

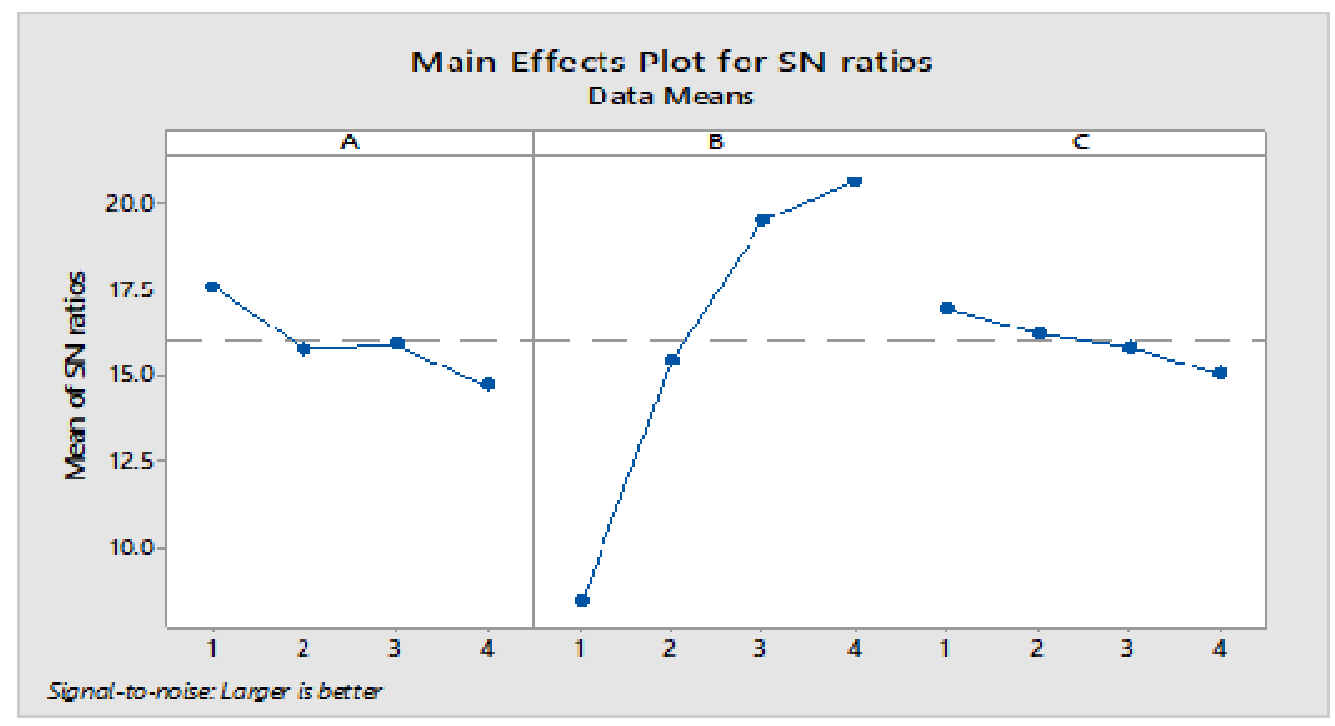

Fig. 5. Optimal setting by Utility-Taguchi theory

\subsection{ANOVA test}

The performance of the model has been verified with the help of R-Sq. value after the evaluation of the sum of squares (SS) and mean square (MS)(Gupta and Kumar, 2015). The R-sq. quantity is termed as the coefficient of determination which is used to examine the performance of the regression model developed(Abhishek et al., 2014; Panda et al., 2016). $0 \leq \mathrm{R}-\mathrm{Sq} . \leq 1$. ANOVA has been carried out to determine the significant contribution of process parameters at the confidence level of $95 \%$ of the experimented results shown in Table 4. From the ANOVA result, it is remarked that the feed rate recognizes as the most effective parameter consisting of the contribution $73.37 \%$, drill speed $3.44 \%$ and FVP $1.16 \%$ of the overall utility. The ANOVA residual plot is shown in Fig 6.

Table 4: ANOVA for overall utility

\begin{tabular}{|c|c|c|c|c|c|c|c|}
\hline Source & DF & Seq SS & Contribution & Adj SS & Adj MS & F-Value & P-Value \\
\hline S & 3 & 2.2074 & $3.44 \%$ & 2.2074 & 0.7358 & 0.31 & 0.816 \\
\hline F & 3 & 47.0393 & $73.37 \%$ & 47.0393 & 15.6798 & 6.66 & 0.024 \\
\hline FVP & 3 & 0.7444 & $1.16 \%$ & 0.7444 & 0.2481 & 0.11 & 0.954 \\
\hline Error & 6 & 14.1253 & $22.03 \%$ & 14.1253 & 2.3542 & & \\
\hline Total & 15 & 64.1164 & $100.00 \%$ & & & & \\
\hline
\end{tabular}




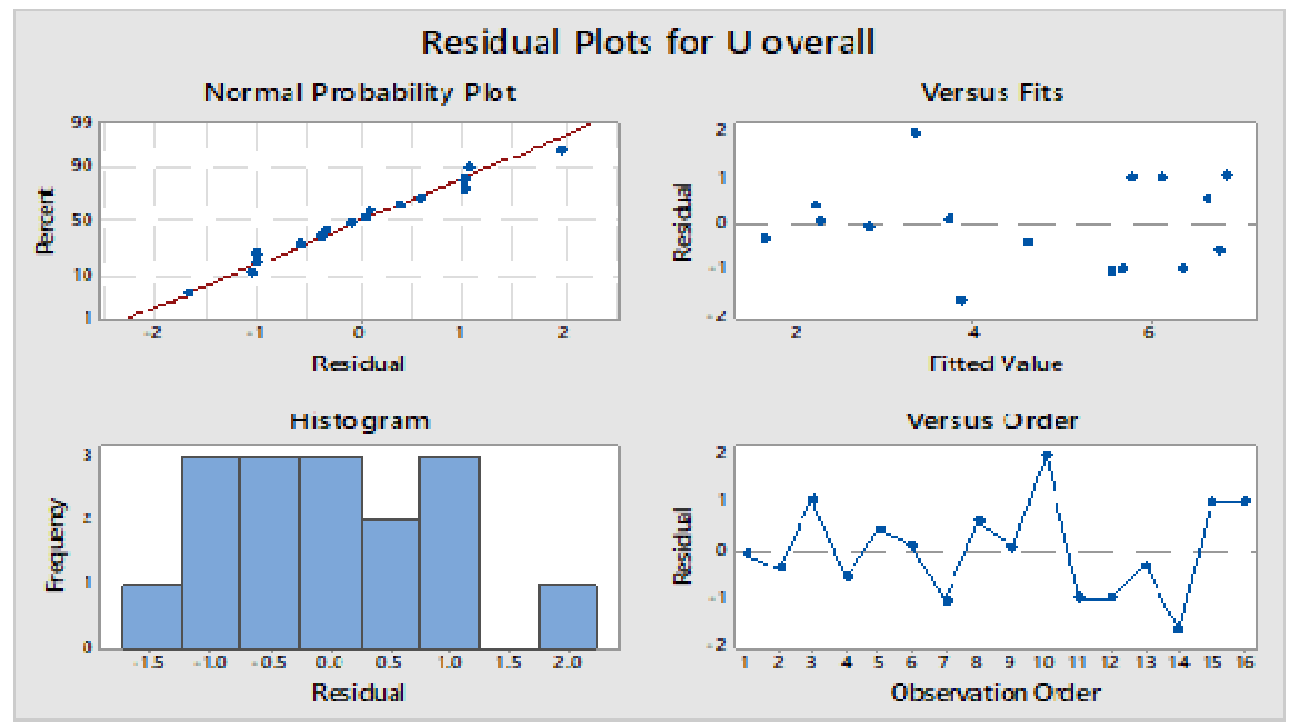

\section{Conclusion}

Fig. 6. Analysis of Variance plot

The work computed the favorable parameter setting to enhance the overall performance of the machined product. This fabrication work has been carried by a molding technique to develop a graphite-epoxy sample and performed drilling operation in a Vertical milling CNC machine. The output characteristics are MRR and Surface roughness. A hybrid optimization technique is used (utility-based Taguchi) to formulate into a single objective function. Based on the obtained results, the conclusion of the work can be drawn as:

- The Utility-based Taguchi method effectively aggregated the conflicting machining characteristics during drilling of graphite composites into a single objective function which is not feasible by the traditional Taguchi method.

- This hybrid approach's optimal parametric setting is observed as A1B4C1 with a good predicted S/N ratio value.

- ANOVA plot depicted that the percentage of contribution in the machining of graphite composites is the most prominent factor that affects the process i.e., feed rate $(73.37 \%)$ and drill speed (3.44\%), respectively.

- The proposed optimization module is found as robust, sustainable, and dominant in producing the optimal process parameters. This proposed hybrid module can be recommended for online and offline quality monitoring of the other conventional and non-conventional manufacturing processes.

\section{Nomenclature}

$\begin{array}{ll}\text { OA } & \text { Orthogonal array } \\ R_{a} & \text { Surface roughness } \\ \text { MRR } & \text { Material removal rate } \\ U & \text { Utility } \\ \text { HB } & \text { higher is better } \\ \text { LB } & \text { Lower is better } \\ \text { ANOVA } & \text { Analysis of variance. }\end{array}$

\section{Acknowledgement}

The authors are very grateful to the National Project Implementation Unit (NPIU), Ministry of Education (MoE), Govt. of India for the sanctioned project (ID-1-5755587331) under the CRS scheme.

\section{References}

Abhishek, K., Datta, S., Mahapatra, S.S., 2014. Optimization of thrust, torque, entry, and exist delamination factor during drilling of CFRP composites. International Journal of Advance Manufacturing Technology, Vol. 76, pp. 401-416. https://doi.org/10.1007/s00170-014-6199-3

Bhatnagar, N., Singh, I., Nayak, D., 2004. Damage investigation in drilling of glass fiber reinforced plastic composite laminates. Materials and Manufacturing Processes. Vol. 19, pp. 995-1007. https://doi.org/10.1081/AMP-200034486

Biswas, A., Bhaumik, S., Majumdar, G., Datta, S., Mahapatra, S.S., 2012. Bead geometry optimization of submerged arc weld: 
Exploration of weighted principal component analysis (WPCA). Applied Mech. Mater. Vol. 110-116, pp. 790-798. https://doi.org/10.4028/www.scientific.net/AMM.110-116.790

Choi, H.Y., Chang, fu K., 1992. A Model for Predicting Damage in Graphite/Epoxy Laminated Composites Resulting from LowVelocity Point Impact. J. Compos. Mater. Vol. 26, pp. 2134-2169. https://doi.org/10.1177/002199839202601408

Ganguli, S., Roy, A.K., Anderson, D.P., 2008. Improved thermal conductivity for chemically functionalized exfoliated graphite/epoxy composites. Carbon N. Y. Vol. 46, pp. 806-817. https://doi.org/10.1016/j.carbon.2008.02.008

Goswami, A., Kumar, J., 2014. Investigation of surface integrity, material removal rate and wire wear ratio for WEDM of Nimonic 80A alloy using GRA and Taguchi method. Eng. Sci. Technol. an Int. J. Vol. 17, pp. 173-184. https://doi.org/10.1016/j.jestch.2014.05.002

Gupta, M., Kumar, S., 2015. Investigation of surface roughness and MRR for turning of UD-GFRP using PCA and Taguchi method. Eng. Sci. Technol. an Int. J. Vol. 18, pp. 70-81. https://doi.org/10.1016/j.jestch.2014.09.006

Hansda, S., Banerjee, S., 2014. Optimizing Multi Characteristics in Drilling of GFRP Composite Using Utility Concept with Taguchi's Approach. Procedia Mater. Sci. Vol. 6, pp. 1476-1488. https://doi.org/10.1016/j.mspro.2014.07.127

Kim, D., 2016. Effect of Tool Wear on Hole Quality in Drilling of Carbon Fiber Reinforced Plastic - Titanium Alloy Stacks Using Tungsten Carbide and Polycrystalline Diamond Tools. J. Manuf. Sci. Eng. Vol. 138, pp. 1-11. https://doi.org/10.1115/1.4031052

Krishnamoorthy, A., Rajendra Boopathy, S., Palanikumar, K., Paulo Davim, J., 2012. Application of grey fuzzy logic for the optimization of drilling parameters for CFRP composites with multiple performance characteristics. Meas. J. Int. Meas. Confed. Vol. 45, pp. 1286-1296. https://doi.org/10.1016/j.measurement.2012.01.008

Krishnaraj, V., Prabukarthi, A., Ramanathan, A., Elanghovan, N., Kumar, M.S., Zitoune, R., Davim, J.P., 2012. Optimization of machining parameters at high speed drilling of carbon fiber reinforced plastic (CFRP) laminates. Compos. Part B Eng. Vol. 43, pp. 1791-1799. https://doi.org/10.1016/j.compositesb.2012.01.007

Kumar, V., Singh, H., 2019. Optimization of rotary ultrasonic drilling of optical glass using Taguchi method and utility approach. Eng. Sci. Technol. an Int. J. Vol. 22, pp. 956-965. https://doi.org/10.1016/j.jestch.2019.02.004

Panda, A., Sahoo, A.K., Rout, A.K., 2016. Investigations on surface quality characteristics with multi-response parametric optimization and correlations. Alexandria Eng. J. Vol. 55, pp. 1625-1633. https://doi.org/10.1016/j.aej.2016.02.008

Rahul, Srivastava, A., Kumar Mishra, D., Chatterjee, S., Datta, S., Bhusan Biswal, B., Sankar Mahapatra, S., 2018. MultiResponse Optimization during Electro-Discharge Machining of Super Alloy Inconel 718: Application of PCA-TOPSIS. Mater. Today Proc. Vol. 5, pp. 4269-4276. https://doi.org/10.1016/j.matpr.2017.11.691

Tserpes, K.I., Labeas, G., Papanikos, P., Kermanidis, T., 2002. Strength prediction of bolted joints in graphite/epoxy composite laminates. Compos. Part B Eng. Vol. 33, pp. 521-529. https://doi.org/10.1016/S1359-8368(02)00033-1

Vasudevan, H., Deshpande, N.C., Rajguru, R.R., 2014. Grey fuzzy multiobjective optimization of process parameters for CNC turning of GFRP/Epoxy Composites. Procedia Eng. Vol. 97, pp. 85-94. https://doi.org/10.1016/j.proeng.2014.12.228

Verma, R.K., Pal, P.K., Kandpal, B.C., 2017. Machining performance optimization in drilling of GFRP composites: A utility theory (UT) based approach. ICCCCM 2016 - 2nd IEEE Int. Conf. Control Comput. Commun. Mater. 1-5. https://doi.org/10.1109/ICCCCM.2016.7918255

\section{Biographical notes}

Mr. Jogendra Kumar is a research cum teaching fellow at Madan Mohan Malaviya University of Technology Department of Mechanical Engineering, Gorakhpur, India. He received his M Tech (Engineering) from MMM University of Tech. in Gorakhpur, India. He is actively interested in teaching and research in the fields of nanomaterials, polymer composites, optimization, advanced machining, machinability aspects of composite materials.

Mr. Prakhar Kumar Kharwar is a research cum teaching fellow at Madan Mohan Malaviya University of Technology Department of Mechanical Engineering, Gorakhpur, India. He received his M Tech (Engineering) from MMM University of Tech. in Gorakhpur, India. He is actively interested in teaching and research in the fields of nanomaterials, polymer composites, optimization, advanced machining, machinability aspects of composite materials.

Dr. Rajesh Kumar Verma is an Associate Professor and Doctoral Supervisor at the Department of Mechanical Engineering at the Madan Mohan Malaviya University of Technology, Gorakhpur, India. He received his Ph.D. (Engineering) from Jadavpur University, Kolkata, India. He is actively involved in teaching and research in nanomaterial, polymer composites, modeling, simulation, optimization, advanced machining, Machinability estimation of composites/nanocomposites materials. He has completed/ongoing more than eight nos. Research and development project sponsored by various govt. agencies. His research proposal secured rank second in Uttar Pradesh- Pollution Control Board (UPPCB) Gomti Nagar, Lucknow in a Hackathon "Beat Plastic Pollution" on 02/10/2018, out of a total of six hundred ninety-nine (699) project entries. Under his supervision, more than 20 students have completed their research works. He has developed various nanomaterials for structural applications and proposed hybrid optimization modules recognized by multiple peer-reviewed journal publishers like Elsevier, Springer, Taylor and Francis, Sage, etc. 